\title{
Haemolysin from Mycobacterium avium complex isolates from AIDS patients
}

\author{
R. G. DESHPANDE, M. B. KHAN, D. A. BHAT and R. G. NAVALKAR
}

Department of Microbiology and Immunology, Morehouse School of Medicine, 720 Westview Drive, Atlanta GA 30310, USA

\begin{abstract}
Cell-bound haemolytic activity was observed in isolates of Mycobacterium avium complex (MAC) from AIDS patients. M. avium type strains showed negligible activity. None of the culture supernates exhibited any haemolytic activity. Zwitterionic detergent 3-[(3-cholamidopropyl)-dimethyl-ammonio]-1-propanesulphonate (CHAPS) was used to extract haemolysin from ethanol-treated $M$. avium complex strain 101 (MAC101) cells. Haemolysin was isolated from CHAPS extract (CE) by metal affinity chromatography and identified as a $32-\mathrm{kDa}$ protein by polyclonal antibodies raised against $M$. tuberculosis haemolysin. Treatment of $\mathrm{CE}$ with trypsin resulted in reduction of haemolytic activity, whereas heating at $100^{\circ} \mathrm{C}$ for $10 \mathrm{~min}$ did not affect its activity. A similar 32-kDa haemolysin was extracted from cells of $M$. avium K128 which was isolated from a monkey infected with simian immunodeficiency virus (SIV). The haemolysin produced by $M$. avium strains isolated from AIDS patients may be associated with the pathogenesis of $M$. avium infection.
\end{abstract}

\section{Introduction}

Organisms belonging to the Mycobacterium avium complex (MAC) are the commonest cause of systemic bacterial infections in AIDS patients [1]. In the nonAIDS population, MAC usually causes pulmonary infection, which in some instances can be diagnosed with a combination of acid-fast staining and culture [2]. However, in immunocompromised patients, it causes a life-threatening tuberculosis-like pulmonary disease as well as local and disseminated infection $[1,3,4]$. The factors involved in causing disseminated infection in AIDS patients in contrast to the localised respiratory infection caused in non-AIDS patients, are not completely understood.

It is unclear what strategies $M$. avium uses to evade being killed by host cells. Cytolysins play an important role in virulence and intracellular survival of bacterial pathogens [5-7]. An earlier report described the isolation of a contact-dependent haemolysin/cytolysin from $M$. tuberculosis [8]. The presence of haemolytic activity in clinical strains of $M$. chelonae and $M$. fortuitum has been reported by Udou [9]. This study examined the haemolytic activity of $M$.

Received 12 June 1997; revised version accepted 28 Aug. 1997

Corresponding author: Professor R. G. Navalkar.

E-mail: navlab@link.msm.edu avium isolates from AIDS patients and from a monkey infected with simian immunodeficiency virus (SIV).

\section{Materials and methods}

Bacterial strains

Seven $M$. avium complex (MAC) isolates (MAC $101-$ serotype 1; LR 535, LR 536, LR 541, LR 542, LR 559 and LR 562 - serotype 4) from AIDS patients were provided by Dr PRJ Gangadharam, University of Illinois, Chicago. Strains ATCC 25291 and 19075 were two $M$. avium type strains of serotype 2. $M$. avium strain K128 isolated from a monkey infected with SIV was kindly provided by Dr G. Newman, Morehouse School of Medicine, Atlanta.

\section{Culture of strains and preparation of extracts}

Each strain was inoculated into Middlebrook $7 \mathrm{H} 9$ Broth (Difco) supplemented with glycerol (without ADC enrichment) and incubated with shaking for 5-6 weeks at $37^{\circ} \mathrm{C}$. The cells were harvested by centrifugation at $8000 \mathrm{~g}$ for $30 \mathrm{~min}$, suspended in phosphatebuffered saline (PBS) and tested for haemolytic activity. At weekly intervals, culture samples of MAC101 and K128 were centrifuged at $8000 \mathrm{~g}$ for $30 \mathrm{~min}$ and the supernates (CS) were tested for haemolytic activity. The cell deposits were incubated in ethanol $50 \% \mathrm{v} / \mathrm{v}$ in $7 \mathrm{H} 9$ broth for $10 \mathrm{~min}$ at $37^{\circ} \mathrm{C}$ 
and centrifuged at $8000 \mathrm{~g}$ for $20 \mathrm{~min}$. The supernate was discarded and the ethanol-treated cells were washed with PBS and extracted with CHAPS $1.5 \%$ in distilled water at $37^{\circ} \mathrm{C}$ for $24 \mathrm{~h}$. The supernate (CE) obtained after centrifugation of the CHAPS-treated cells was stored at $10^{\circ} \mathrm{C}$.

\section{Assay for haemolytic activity}

One $\mathrm{ml}$ of bacteria $\left(10^{10} / \mathrm{ml}\right)$ suspended in PBS was mixed with $1 \mathrm{ml}$ of sheep red blood cells (RBCs) $0.7 \%$ in PBS containing bovine serum albumin $0.5 \%$, cosedimented by centrifugation at $8000 \mathrm{~g}$ for $10 \mathrm{~min}$ and incubated at $37^{\circ} \mathrm{C}$ for $12-16 \mathrm{~h}$. The haemolytic activity of CSs and CEs was assayed by mixing $0.25 \mathrm{ml}$ of $\mathrm{CE}$ or $1 \mathrm{ml}$ of CS with RBCs and incubating the mixture at $37^{\circ} \mathrm{C}$ for $12-16 \mathrm{~h}$. The samples were then centrifuged and the $\mathrm{E}_{540}$ of the supernates measured as an indicator of the release of haemoglobin from lysed erythrocytes with PBS as a blank. Appropriate controls (RBCs in PBS, RBCs mixed with $7 \mathrm{H} 9$ broth and RBCs mixed with CHAPS $1.5 \%$ ) were treated similarly.

\section{Immobilised metal affinity chromatography (IMAC)}

Haemolytic activity was isolated from CE of MAC101 and $\mathrm{K} 128$ by IMAC with nickel nitrilotriacetic acid (Ni-NTA) resin under non-denaturing conditions [10]. One $\mathrm{ml}$ of unfiltered $\mathrm{CE}$ mixed with $1 \mathrm{ml}$ of buffer $\mathrm{A}$ $(0.5 \mathrm{M}$ sodium phosphate buffer containing $0.5 \mathrm{M} \mathrm{NaCl}$, $\mathrm{pH}$ 8.0) was loaded on to a Ni-NTA column. Bound protein was eluted with buffer $\mathrm{B}(10 \mathrm{mM}$ potassium phosphate buffer containing $0.75 \mathrm{M} \mathrm{NH} \mathrm{N}_{4} \mathrm{Cl}, \mathrm{pH}$ 6.6) and collected in $1-\mathrm{ml}$ fractions. Fractions $(0.25-\mathrm{ml}$ amounts) were tested for haemolytic activity with and without the addition of CHAPS $0.5 \%$. Ten $\mu \mathrm{l}$ of fractions with haemolytic activity were analysed by SDS-PAGE (12\%, Mini-Protean II ready gels, BioRad) followed by silver staining and immunoblotting.

\section{Results}

Cells of $M$. avium complex strain 101 (MAC101), $M$. avium $\mathrm{K} 128$ and six clinical isolates of MAC from AIDS patients showed strong haemolysis of sheep RBCs $\left(E_{540}=0.3-0.6\right)$ when compared to control RBCs incubated in PBS $\left(E_{540}=0.06\right)$. Both the $M$. avium serotype 2 strains showed negligible haemolytic activity $\left(\mathrm{E}_{540}=0.16\right.$ and 0.18 , respectively). No haemolytic activity $\left(\mathrm{E}_{540}=0.12-0.16\right)$ was demonstrated for CSs of any of the strains even after growth for 5 weeks as compared to the $7 \mathrm{H} 9$ broth control $\left(\mathrm{E}_{540}=0.13\right)$. However, CSs from 6-week-old cultures lysed sheep RBCs $\left(E_{540}=0.22-0.29\right)$. At this time the cells had autolysed as determined by acid-fast staining. The haemolytic activity of MAC101 could not be solubilised by sonication or treatment with $8 \mathrm{M}$ urea or ethanol or with detergents such as Tween 20 or Tween
80. The zwitterionic detergent CHAPS at a concentration of $1.5 \%$ extracted activity after incubation for $12 \mathrm{~h}$ at $37^{\circ} \mathrm{C}$ from MAC101 cells pre-treated with ethanol $\left(\mathrm{E}_{540}\right.$ of $\left.\mathrm{CE}=0.6\right)$. CHAPS $1.5 \%$ alone did not lyse RBCs $\left(E_{540}=0.08\right)$. Cell debris obtained after treatment of ethanol-treated cells with CHAPS did not show any haemolytic activity $\left(\mathrm{E}_{540}=0.08\right)$. Sterilising $\mathrm{CE}$ through $0.45-\mu \mathrm{m}$ pore filters caused loss of haemolytic activity. However, addition of CHAPS $0.5 \%$ to the filtered CE restored activity. Therefore, all solubilised haemolysin preparations were used without filtersterilisation. Heating $\mathrm{CE}$ at $100^{\circ} \mathrm{C}$ for $10 \mathrm{~min}$ did not affect activity $\left(E_{540}=0.55\right)$. Treatment of $\mathrm{CE}$ with trypsin $(0.1 \mathrm{ml}$ of $1 \mathrm{mg} / \mathrm{ml}$ in PBS, pH 7.6$)$ at $37^{\circ} \mathrm{C}$ for $30 \mathrm{~min}$ caused a reduction in haemolytic activity $\left(\mathrm{E}_{540}=0.25\right)$. CE of strain $\mathrm{K} 128$ prepared similarly also showed significant haemolytic activity $\left(\mathrm{E}_{540}=\right.$ $0.5)$.

IMAC of MAC101 CE on Ni-NTA yielded a single peak eluting in the first two-to-three fractions. Each of these fractions showed strong haemolytic activity $\left(E_{540}\right.$ of $0.25 \mathrm{ml}$ of each fraction $\left.=0.3-0.4\right)$ only after addition of CHAPS $0.5 \%$. Fractions tested for activity without the addition of CHAPS did not show any activity $\left(\mathrm{E}_{540}=0.09\right)$. Elution of $\mathrm{K} 128 \mathrm{CE}$ from Ni-NTA column yielded two consecutive fractions, both of which were haemolytic $\left(E_{540}\right.$ of $0.25 \mathrm{ml}$ of each fraction $=0.3$ and 0.28 ). All the haemolytic fractions of MAC101 and K128 had identical SDSPAGE profiles with protein bands in the $\mathrm{M}_{\mathrm{r}}$ range $c$. 30000 (data not shown). Therefore, the fractions of each strain were pooled. Silver staining of the pooled fractions after SDS-PAGE is shown in Fig. 1(A). Western blotting of the haemolytic fractions of strains MAC101 and K128 with polyclonal antiserum to $M$. tuberculosis haemolysin [8] showed a single band with $\mathrm{M}_{\mathrm{r}}$ of c. 32000 (Fig. 1B).

\section{Discussion}

The importance of MAC-associated disease has been magnified dramatically by the AIDS epidemic. During our investigation into the presence of haemolysin in mycobacteria, it was observed that MAC isolates from AIDS patients showed significantly more lysis of sheep erythrocytes than $M$. avium type strains. Furthermore, a strain of $M$. avium (K128) isolated from a monkey infected with SIV also showed strong haemolytic activity.

Both MAC101 and K128 demonstrated strong cellassociated haemolytic activity which could be extracted with CHAPS $1.5 \%$ only after pre-treating the cells with ethanol. Haemolytic activity was not secreted into the medium until after the onset of autolysis. MAC101 and K128 haemolysins share an epitope with $M$. tuberculosis haemolysin because they were recognised by polyclonal antiserum raised 

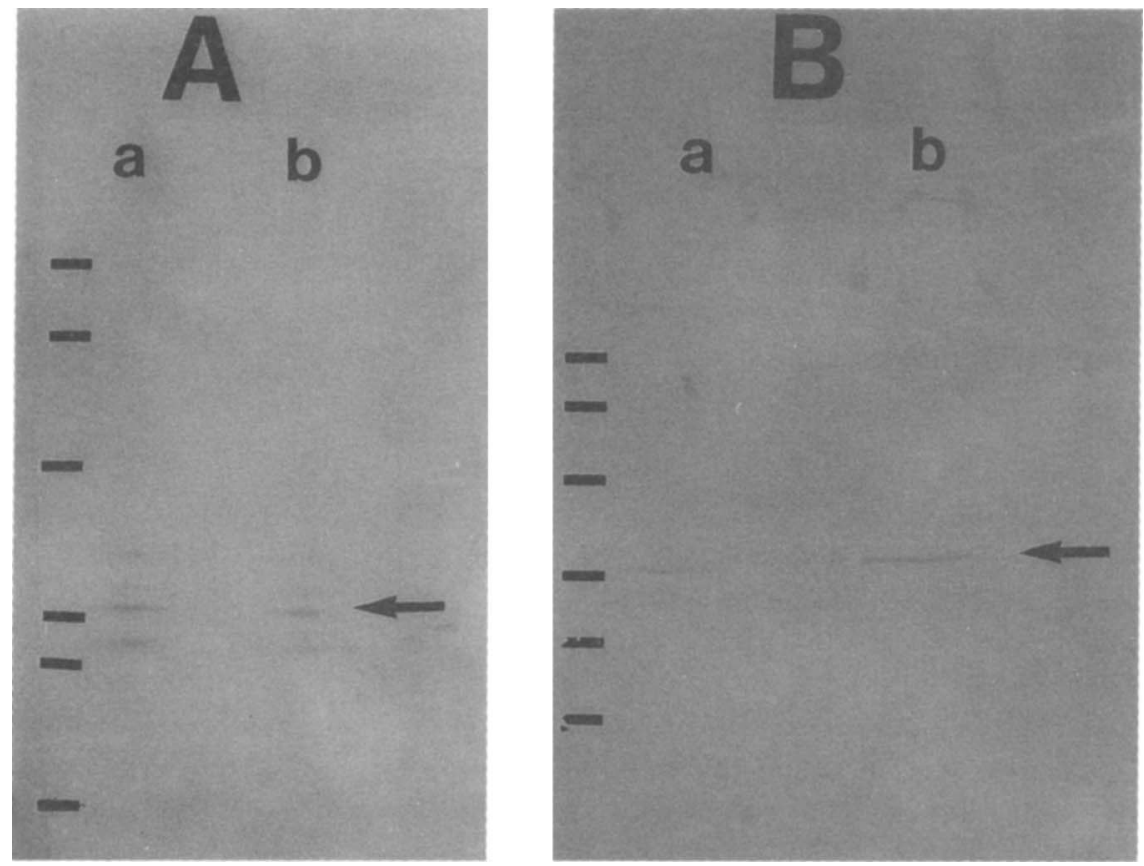

Fig. 1(A). SDS-PAGE (12\%) and silver staining of haemolytic fractions of (a) MAC101 and (b) K128 obtained from $\mathrm{Ni}-\mathrm{NTA}$ column. The arrow indicates the $32-\mathrm{kDa}$ band. (B) Immunoblot of haemolytic fractions obtained after IMAC of (a) MAC101 and (b) K128 with polyclonal antibody against $M$. tuberculosis haemolysin. The arrow indicates the 32-kDa band. Positions of the mol.wt markers $(\mathrm{kDa})$ are indicated on the left in each panel (top to bottom: phosphorylase b, 97; BSA, 66.2; ovalbumin, 43; carbonic anhydrase, 31; soybean trypsin inhibitor, $21.5 \%$; lysozyme, 14.4).

against $M$. tuberculosis haemolysin. However, the haemolysin of both the $M$. avium strains appear to be different from $M$. tuberculosis haemolysin, as they bound to Ni-NTA resin whereas the latter did not [8]. Because Ni-NTA binds proteins containing surfaceexposed neighbouring histidine residues [11], it is probable that $M$. avium haemolysin possesses such residues. Ni-NTA resin can, therefore, be used as a quick step to isolate $M$. avium haemolysin and for differentiation between $M$. avium and $M$. tuberculosis haemolysins.

The exact location of haemolysin within the cell is not known. The difficulty in its solubilisation suggests that it is an integral membrane protein which can be extracted only after disruption of the lipid bilayer by ethanol. Most detergents even in combination with a denaturing agent such as urea were unable to solubilise it. Haemolysin of $M$. avium appears to be a very stable enzyme which retains its activity even after treatment with denaturing agents, detergents and organic solvents. Extended studies on MAC haemolysin, the gene(s) that encode it and its effect(s) on host cells may provide important insights into the pathogenesis and virulence of $M$. avium as haemolysins are important virulence factors among other intracellular pathogens $[5,7]$.

This work was supported by the US Leprosy Panel of the US-Japan Co-operative Medical Service Program, administered by the National Institute of Allergy and Infectious Disease (Grant AI27189), and in part by the Association of Minority Health Profession Schools (AMHPS) AIDS Consortium, Minority Biomedical Research Support
(MBRS GM08248) and Research Centers for Minority Institutions (NIH/NCRR no. RR03034)

\section{References}

1. Young LS, Inderlied CB, Berlin OG, Gottlieb MS. Mycobacterial infections in AIDS patients, with an emphasis on the Mycobacterium avium complex. Rev Infect Dis 1986; 8: 1024-1033.

2. Rosenzweig DY. Pulmonary mycobacterial infections due to Mycobacterium intracellulare-avium complex. Clinical features and course in 100 consecutive cases. Chest 1979; 75: 115-119.

3. Hawkins CC, Gold JWM, Whimbey E et al. Mycobacterium avium complex infections in patients with the acquired immunodeficiency syndrome. Ann Intern Med 1986; 105: 184-188.

4. Wolinsky E. Nontuberculous mycobacteria and associated diseases. Am Rev Respir Dis 1979; 119: 107-159.

5. Cossart P, Vicente MF, Mengaud J, Baquero F, Perez-Diaz JC, Berche P. Listeriolysin $\mathrm{O}$ is essential for virulence of Listeria monocytogenes: direct evidence obtained by gene complementation. Infect Immun 1989; 57: 3629-3636.

6. Welch RA. Pore-forming cytolysins of gram-negative bacteria. Mol Microbiol 1991; 5: 521-528.

7. Welch RA, Falkow S. Characterization of Escherichia coli hemolysins conferring quantitative differences in virulence. Infect Immun 1984; 43: 156-160.

8. Deshpande RG, Khan MB, Bhat DA, Navalkar RG. Isolation of a contact-dependent haemolysin from Mycobacterium tuberculosis. J Med Microbiol 1997; 46: 233-238.

9. Udou T. Extracellular hemolytic activity in rapidly growing mycobacteria. Can J Microbiol 1994; 40: 318-321.

10. Deshpande RG, Khan MB, Bhat DA, Navalkar RG. Purification and partial characterisation of a novel $66-\mathrm{kDa}$ seroreactive protein of Mycobacterium tuberculosis $\mathrm{H}_{37} \mathrm{Rv}$. J Med Microbiol 1994; 41: 173-178.

11. Hochuli E, Dobeli H, Schacher A. New metal chelate adsorbent selective for proteins and peptides containing neighboring histidine residues. $J$ Chromatogr 1987; 411: $177-184$ 